\title{
Prologue 2
}

Economic globalization and the development of information technology have enabled cities to achieve greater and greater significance in global economic activities. With increasingly fierce competition among cities, improving urban competitiveness is becoming an important strategic issue to cities, companies and countries in the world. To conduct further research and discussion on this issue, Professor Peter Karl Kresl and I initiated the Global Urban Competitiveness Research Project (GUCP) group, made up of scholars with interests in urban competitiveness from several countries. We decided to hold an international forum on urban competitiveness every year. To provide global cities, companies and the public with comparative information and decision-making reference on urban competitiveness, we decided to release a Global Urban Competitiveness Report every two years. It is a hard and pioneering job. The report for the years 2007-08 was completed by members of the Secretariat under the leadership of Professor Pengfei $\mathrm{Ni}$, the General Secretary of GUCP. Great support and assistance has been received from Professor Kresl and members of the GUCP, the Chinese Academy of Social Sciences (CASS) and its Finance and Trade Institute, urban research experts from several countries, and governments of some major cities in the world. The Report was made possible by more than one year of efforts on theoretical innovation, data collection, on-site investigation, and data processing and analysis.

A comprehensive comparison on 500 cities in the world, focused analysis on 150 cities, and case studies on the top ten cities of urban competitiveness are available in the Global Urban Competitiveness Report - 2010.

The research has received great support from many cities in the world. After determining sample cities, the project group contacted mayors and officials of involved cities, including London, Sydney, Vienna, Zurich, Paris, Hamburg, Glasgow, Florence, Toronto and Vancouver, and received responses. The involved cities provided support, responded with related materials or appointed their representatives in China to contact us. In 2007, the project group visited Canada and conducted on-site investigations there. Federal authorities, the Mayor of Toronto and officials of Vancouver met members of the project group and introduced information on urban development to them. In 2008 local authorities of some cities in Europe welcomed queries from the GUCP. After determining the topic, they started the work of finding global partners. Around 100 scholars around the world have joined the research.

The research work is tremendous and features great difficulties. The secretariat has recruited around 100 graduate students from universities in Beijing and other areas of China to accomplish the research. After more than one year of great effort, the work was completed on time. Professor Pengfei Ni decided the basic theories, index system, research framework and key conclusions. Dr Qinghu Hou worked on econometrics. Dr Fengyong Lv, Dr Jin Huang and Ms Xiaolan Yang collected and organized the data. Yao Zhang, Jie Gao and Zizhong Wang coordinated the compiling and editing efforts. 
After refining the theories, collecting data, making econometric analyses and drawing main conclusions, the authors accomplished the compilation of the Report, and they are listed as follows: Pengfei Ni, Qinghu Hou, Fengyong Lv, Jin Huang, Yang Xiaolan, Yao Zhang, Wu Zhang and Jie Gao.

Finally, Professor Peter Karl Kresl, Professor Pengfei Ni and Professor Jianfa Shen revised and edited the Report in English.

Although we have tried our best to accomplish the task, there may still be room for improvement in the Report due to the limitation of our ability. We are looking forward to comments and suggestions from global municipal officials and urban research experts. Your input will help greatly in turning the Report into one of the most useful references on global urban development.

Pengfei Ni

General Secretary, GUCP

Professor of Economics, Chinese Academy of Social Sciences 